\title{
Polar maps of C-band backscatter parameters from the Advanced Scatterometer
}

\author{
Jessica Cartwright ${ }^{1,2,3 \dagger}$ Alexander D. Fraser ${ }^{4,5,3}$
}

${ }^{1}$ National Oceanography Centre, European Way, Southampton, SO14 3ZH, UK

$5{ }^{2}$ Ocean and Earth Science, National Oceanography Centre Southampton, University of Southampton, Southampton, SO14 3ZH, UK

${ }^{3}$ Antarctic Climate \& Ecosystems Cooperative Research Centre, University of Tasmania, Private Bag 80, Hobart, Tasmania 7001, Australia

${ }^{4}$ Australian Antarctic Program Partnership, Institute for Marine and Antarctic Studies, University of Tasmania, Hobart,

10 Tasmania, Australia

${ }^{5}$ Institute for Marine and Antarctic Studies, University of Tasmania, Hobart, Tasmania, Australia

Correspondence to: Jessica Cartwright (jessica.cartwright@ spire.com)

Abstract. Maps of backscatter anisotropy parameters from the European Organisation for the Exploitation of Meteorological

15 Satellites (EUMETSAT) Advanced Scatterometer (ASCAT), a C-band fan-beam scatterometer, contain unique and valuable data characterising the surface and subsurface of various cryospheric elements, including sea ice and ice sheets. The computational expense and considerable complexity required to produce parameter maps from the raw backscatter data inhibits the wider adoption of ASCAT data. Here, backscatter anisotropy parameter maps gridded at a resolution of $12.5 \mathrm{~km}$ per pixel are made available to the community in order to facilitate the exploitation of these parameters for cryospheric applications.

20 These maps have been calculated from the EUMETSAT Level 1B sigma0 product acquired from ASCAT on board MetOpA, MetOp-B and MetOp-C. The dataset is unique in that it prioritises anisotropy characterisation over temporal resolution, and combines ASCAT data from multiple platforms. The parameterisation chosen assumes a linear falloff of backscatter with incidence angle and a 4th order Fourier series parameterisation of azimuth angle anisotropy. The product (Fraser and Cartwright, 2021) is available at https://doi.org/10.26179/5dd60df7469e2 presented on three time scales depending on orbital

25 platform availability: 5-day (2007 to present - MetOp-A only - suitable for users requiring a long time-series), 2-day (2013 to present - MetOp-A and -B), and 1-day resolution (2019 - present - MetOp -A, -B and -C - suitable for users needing both high temporal resolution and detailed anisitropy characterisation).

\section{Introduction}

Observation and characterisation of the polar cryosphere is of critical importance in understanding changes to the Earth's climate system. The extent, variability and physical characteristics of snow and ice (and their trends), both grounded and

$\dagger \quad$ Current Address: Spire Global Inc., Glasgow, UK 
https://doi.org/10.5194/essd-2021-92

Preprint. Discussion started: 31 March 2021

(c) Author(s) 2021. CC BY 4.0 License.

floating, have far-reaching climatic consequences, and can respond relatively rapidly to changes in atmospheric and oceanic forcing (Pörtner et al., 2019). Baseline characterisation of the physical properties of sea ice is increasingly important due to the recognition of the wide roles it plays in the physics of the Earth's climate, e.g. through the modification of the surface albedo (Stroeve et al., 2011), and its impact on the ocean circulation and weather (Comiso et al., 2003). From a human perspective, there is also great interest in understanding Arctic sea ice for oil and gas exploitation and shipping routes (Bird et al., 2008). The Greenland Ice Sheet and parts of the Antarctic Ice Sheet are also undergoing profound changes in response to atmospheric and oceanic forcing, in the form of enhanced melt (both supra-glacial and sub-glacial in ice shelf cavities), resulting in mass loss and contributions to sea level rise (Holland et al., 2019; Shepherd et al., 2020).

The extent and remoteness of the polar cryosphere means that effective hemispheric, repeat monitoring and characterisation

40 of these cryospheric elements can be provided only by spaceborne sensors. The cryosphere is currently observed by a range of spaceborne active and passive sensors, and across a wide swath of the electromagnetic spectrum (Lubin and Massom (2006) and Massom and Lubin (2005)). Each part of the spectrum is associated with a unique set of characteristics (e.g., ground resolution, cloud penetration, ice/snow penetration, response to ice properties, ease of interpretation). Here we draw attention to the useful physical characteristics which can be retrieved by non-nadir C-band ( $\sim 5 \mathrm{GHz})$ radar backscatter cross-section (hereafter simply "backscatter") in order to provide context for the interpretation of the dataset accompanying this paper.

\section{C-band backscatter}

The interaction of incident C-band radiation with a target (including both surfaces and subsurface volumes) depends on both the dielectric properties and physical structure of the target. In addition, depending on the physical properties of the target, Cband backscatter can exhibit strong anisotropy (i.e., as observation geometry-dependent measure of backscatter). This can manifest as anisotropy as a function of incidence angle, azimuth angle, or both, depending on the properties of the target. If the processes governing the anisotropy are well-understood, characterisation of this anisotropy can inform on the nature of the target. A further motivation for fully characterising the anisotropy is the removal of elements of the anisotropy, to retrieve an estimate of backscatter "uncontaminated" by those elements of anisotropy.

A wide variety of parameterisations of the microwave backscatter anisotropy from the Antarctic continent are reviewed in

55 Fraser et al. (2014). To briefly summarise, incidence angle anisotropy at intermediate incidence angle ranges used by scatterometers (e.g., 25 to 65 degrees) is widely modelled as a linear change with respect to incidence angle. Azimuthal anisotropy arises primarily due to the interaction between the incident microwave radiation and regularly aligned roughness (on the Rayleigh roughness scale, or larger) of the surface and subsurfaces within the penetration depth (Bingham and Drinkwater, 2000; Fraser et al., 2016; Partington and Flach, 2003; Ulaby et al., 1996; Yurchak, 2009). Where incident

60 microwaves are perpendicular to this structured roughness, higher backscatter results. Such structured alignment is commonly encountered in sand dune systems, croplands (Bartalis et al., 2006) and over the Greenland and Antarctic ice sheets, in the form of sastrugi (Long and Drinkwater, 2000). This relationship is exploited over oceans, where ocean capillary wave 
https://doi.org/10.5194/essd-2021-92

Preprint. Discussion started: 31 March 2021

(c) Author(s) 2021. CC BY 4.0 License.

(c) (i)

properties (height and alignment) are a function of the near-surface wind field. Scatterometer-based remote retrieval of azimuthal anisotropy over oceans, with real-time data from sensors such as ASCAT thought to have increased weather forecast

65 accuracies by as much as 30\% through the monitoring of near-surface winds over the ocean (Figa-Saldaña et al., 2002).

\subsection{Applications of Scatterometery to the Cryosphere}

The following section provides a brief overview of interpreting backscatter anisotropy of the polar cryosphere (including sea ice and glacial ice sheets). For further information, the readers are referred to in-depth reviews of the topic provided by Long (2017) and Alley (2017). Here, we aim for a broad overview with sufficient context to understand the ASCAT-based dataset

70 accompanying this paper.

Backscatter and anisotropy vary greatly between glacial ice, sea ice, dry snow and moisture-laden snow on sea ice, but also more subtly within each of these surface types. A primary signal characteristic to consider is the penetration depth of the signal into the medium. This determines whether the received signal is dominated by volume or surface scattering. For dry snow and glacial ice, there is on the order of 20 metres of penetration at C-band (Müller et al., 2010; Rignot et al., 2001), meaning

75 backscatter has a considerable contribution from both internal layers of varying structure and density (surface scattering), as well as considerable volume backscatter. This penetration depth combined with the similar dielectric properties of air and dry snow mean that in smoother regions of the Antarctic continent, the majority of signal received can be from volume rather than surface scattering (Drinkwater et al., 2001; Rott et al., 1993). This allows for C-band incidence angle anisotropy to be effective for surface mass balance retrieval, via sensitivity to both snow grain size and the presence of dielectric layering, both of which

80 are modified by the magnitude of the surface mass balance (Drinkwater et al., 2001; Mätzler and Hüppi, 1989).

Surface contributions (including those from buried surfaces such as sastrugi) are highly dependent on surface orientation and slope, Rayleigh scale roughness, and roughness anisotropy (Ashcraft and Long, 2006); enabling facies determination and sastrugi property retrieval (Ledroit et al., 1993; Remy et al., 1992). Surface scattering tends to dominate where penetration depth is minimal, such as over sea ice, yielding information on the degree of deformation of the ice itself. Backscatter is also

85 greatly reduced by the incorporation of liquid water within the scattering volume (Alley et al., 2018; Trusel et al., 2012). Data collected during the sea ice melt season or areas of ice sheet experiencing melt must therefore be treated appropriately. Icebergs are easily identifiable with simple thresholding techniques through their very high backscatter signatures (due to melt and refreeze) in comparison with the lower backscatter of sea ice (Budge and Long, 2018; Young and Hyland, 1997). Such studies are limited by the relatively low resolution of scatterometers; moderate-sized icebergs (up to $\sim 2 \mathrm{~km}$ ) are generally subpixel at the resolution of scatterometer datasets. Where higher resolution microwave backscatter data are required for iceberg discrimination, it is generally necessary to use spaceborne synthetic aperture radar (SAR) instruments (Budge and Long, 2018; Young and Hyland, 1997), however larger icebergs may be resolved in scatterometer data with the use of resolution enhancement techniques, e.g., Long et al. (1993). 
https://doi.org/10.5194/essd-2021-92

Preprint. Discussion started: 31 March 2021

(c) Author(s) 2021. CC BY 4.0 License.

(c) (i)

\subsection{C-band sensors}

95 There are three classes of active instrument using C-band: SAR, altimeters and scatterometers. SAR allows the collection of extremely high resolution imagery of the surface through the artificial extension of the antenna by the motion of the radar itself. This creates a very high data volume over a narrow swath, which is typically unsuitable for application over large areas. The data also provide minimal incidence and azimuth angle diversity, precluding characterisation of the microwave backscatter anisotropy detailed above. Altimeters measure backscatter at a nadir (or near-nadir) incidence angle, again providing no diversity of incidence/azimuth angle and precluding characterisation of anisotropy.

Scatterometers enable the collection of radar backscatter data at a variety of azimuth angles but at relatively low spatial resolution compared to SAR. Compared to SAR, scatterometers are generally better suited to large-scale studies, with a spatial resolution of typically $\sim 30 \mathrm{~km}$, but potential for below $10 \mathrm{~km}$ (Long et al., 1993). These sensors take two main forms - a rotating pencil-beam - such as SeaWinds (Spencer et al., 1997) and a sweeping fan beam (e.g. SeaSat Scatterometer, NASA

105 Scatterometer, European Remote Sensing Satellite-1 or Advanced Scatterometer). In the case of pencil beam scatterometry, the diversity of azimuth angle measurements comes from the (azimuthal) rotation of the antenna. As such, pencil-beam scatterometers are typically limited in incidence angle diversity. Fan-beam scatterometers use multiple fixed antennae at different orientations allowing multiple looks at each pixel in a swath-like signal. This configuration combined with the spacecraft orbit means that over a given time interval, backscatter from a point on the surface is measured from a wide variety

110 of both incidence ( 25 to 65 degrees for ASCAT) and azimuth angles (azimuth range dependent on latitude of observation, see Fraser et al. (2014)).

The processing of scatterometer data is highly computationally expensive due to the large quantities of data involved and processing time required for multivariate parameter estimation. Choice of parameterisation model is not straight-forward, with a wide variety covered by Fraser et al. (2014), however this dataset aims to make scatterometry data more accessible to the

115 cryosphere research community through the computation of broadly-applicable parameters over both polar areas using an anisotropy model with proven applications in cryospheric remote sensing (Fraser et al., 2016; Fraser et al., 2014). It is anticipated that the provision of this dataset will enable the increased exploitation of scatterometry for cryosphere research purposes over a variety of time scales at as high a temporal resolution as possible, whilst retaining $100 \%$ coverage at 5- and 2day timescales and $>92 \%$ coverage at daily resolution.

\subsection{Previous similar datasets}

Several ASCAT-based backscatter datasets exist, but are either:

a) low-level unprocessed data - i.e., anisotropy-affected raw backscattering cross section measurements, such as the source data used here; 
b) based on simple anisotropy parameterisations and containing unaccounted-for azimuthal anisotropy - for example those distributed by the Centre de Recherche et d'Exploitation Satellitaire (CERSAT) and the National Aeronautics and Space Administration Scatterometer Climate Record Pathfinder Project (NASA SCP);

c) highly processed end-product datasets representing retrieved physical quantities - e.g., sea ice extent, Arctic sea ice type, ocean wind and soil moisture parameters, etc. (OSI SAF, 2019a, b).

Our dataset represents a balance between these product types, providing the computationally-expensive parameter calculation whilst making minimal assumptions regarding the physical meaning of the parameters presented and accounting for anisotropy from both incidence and azimuth angles. It is anticipated that this dataset will facilitate exploitation of ASCAT data for cryospheric parameter retrieval. A trade-off we make in performing a detailed anisotropy characterisation is the preclusion of parameter retrieval in regions with a limited number of observations. We retrieve a total of 8 parameters, so require at least 8 observations of the surface for parameter estimation to occur. This, in turn, requires at least three ASCAT passes (each pass gives three unique observations). Datasets normalising only by incidence angle (e.g. CERSAT and NASA SCP) require only one pass to provide sufficient observations, yielding marginally higher coverage at latitudes further from the geographical pole.

Data from ASCAT are currently used for the characterisation of global sea ice extent, as well as ice type retrieval in the Northern Hemisphere (Breivik et al., 2012). These products are routinely produced, and available from Ocean and Sea Ice

140 Satellite Application Facility (OSI SAF - www.osi-saf.org). Ice extent calculations exploit the difference in backscatter received by the fore and rear antennas in combination with passive microwave sensors. A Bayesian methodology is applied with the use of training areas to identify sea ice, open water, and in the Northern Hemisphere, sea ice type (Breivik et al., 2012). Similar parameters to those used by OSI SAF for the creation of these products may be extracted from the more comprehensive parameterisation presented here.

145 We note that resolution-enhanced ASCAT products exist (Long et al., 1993; Vogelzang and Stoffelen, 2017) but emphasise that the present dataset focusses not on resolution but a relatively detailed parameterisation (to ensure minimal residual anisotropy), and parameter estimation with the shortest possible time interval, which is determined by the number of MetOp platforms operational at the time. In future work we hope to combine all three attributes for enhanced spatial resolution, complex parameterisation and high temporal resolution.

\section{ASCAT and Metop-A, -B and -C platforms}

The backscatter data used in this study are acquired from the Advanced SCATterometer (ASCAT) onboard Metop-A, -B and -C. These three satellites have been put into orbit at an inclination of $98.2^{\circ}$ and an altitude of $817 \mathrm{~km}$ into sun-synchronous orbits with a period of 101 minutes (Figa-Saldaña et al., 2002). Each satellite has a 29-day repeat cycle, and a 5-day subcycle. The launch dates and data availability of each of the three satellites can be seen in Table 1 below, with the overlapping periods 
https://doi.org/10.5194/essd-2021-92

Preprint. Discussion started: 31 March 2021

(c) Author(s) 2021. CC BY 4.0 License.

(c) (i)

maps (MetOp-A and -B), and daily resolution as data become available from MetOp-C. MetOp-B and -C are in the same plane, spaced approximately half an orbit apart. Thus, with this pair alone, polar observations are provided every $\sim 50$ minutes. MetOp-A shares its period and inclination with -B and -C but has been drifting since 2017 to facilitate extension of its lifetime. It is now in a different plane but still providing high-quality backscatter measurements. The tri-platform observation network is projected to be operational until 2022.

Table 1: Launch dates of MetOp-A, MetOp-B and MetOp-C and data availability from each. *MetOp-A data are of suspected poorer calibration prior to July 2007 and not used here (Fraser et al., 2016). As only 15 days of data are available from MetOp-B in 2012, 2-day processing is instead started from 2013.

\begin{tabular}{lll} 
Platform & Launched & Data Available \\
\hline \hline MetOp-A & October 2006 & March 2007* - Present; \\
MetOp-B & September 2012 & December 2012-Present \\
MetOp-C & November 2018 & June 2019 - Present
\end{tabular}

165

ASCAT is a C-band $(5.255 \mathrm{GHz}) \mathrm{VV}$-polarisation scatterometer with six fan-beam antennas. The antennas give a two-swath configuration, each approximately $550 \mathrm{~km}$ wide, with a $720 \mathrm{~km}$ sub-satellite gap, measuring backscatter up to $88^{\circ} \mathrm{N} / \mathrm{S}$. Three antenna pairs on each side $\left( \pm 45^{\circ}, \pm 90^{\circ}\right.$ and $\pm 135^{\circ}$ of azimuth relative to the sub-satellite track) give a wide variety of azimuth and incidence angles $\left(25-65^{\circ}\right)$, seen in Figure 5. Over a 5-day subcycle, these provide many looks of a region of the Earth's surface with a high diversity of both incidence and azimuth angles (Fraser et al., 2014). The current half-orbit (50 minute) spacing of MetOp-B and -C gives highly complementary coverage of polar regions: i.e., a 50 minute interval corresponds to an Earth rotation of 12.5 degrees. At a latitude of $65^{\circ}(\mathrm{N}$ or S), a 12.5 degree rotation corresponds to a distance of $\sim 580 \mathrm{~km}$, thus at this latitude, MetOp-B and -C observe within each other's sub-satellite gap during subsequent passes. As MetOp-A's orbit is drifting, this increases the diversity of observations and allows daily maps of the parameters given here, although the phasing of the orbit (and hence the degree to which is can be considered complementary) will drift over time.

\section{Methods}

Data were acquired in NetCDF format from the EUMETSAT Data Centre ("ASCAT GDS Level 1 Sigma0 resampled at 12.5 km Swath Grid - Metop"), data code ASCSZR1B. The $12.5 \mathrm{~km}$ resampled product is used here. The processing required to reach the resampled product results in a true spatial resolution of $25-30 \mathrm{~km}$, as the full resolution product is smoothed in both the across- and along- track directions for gridding. There are approximately 14 complete-orbit files per day, starting and ending near the North Pole. These files contain geographic location data for each pixel, as well as azimuth, incidence, $\sigma_{0}$ (Normalised Radar Cross Section or NRCS - here termed backscatter) and $K_{p}$ (Residual Mean Square of the NRCS) values in the format of triplets (fore, mid and aft antennas), each with 82 data points per row. 
The ASCAT swath data are then resampled onto the NSIDC polar stereographic $12.5 \mathrm{~km}$ grid version 3 (https://nsidc.org/data/polar-stereo/ps_grids.html). This is performed separately for the northern and southern hemisphere data, with true latitude at $70^{\circ}$ for each hemisphere. This grid was chosen in order to ensure wide availability of compatibility of other sea ice datasets, as well as ensuring minimal distortion of the grid in the sea ice region. This grid is 608 x 896 pixels in the northern hemisphere and $632 \times 664$ pixels in the southern hemisphere.

In regions exhibiting backscatter anisotropy, backscatter varies with incidence and azimuth angle, and such anisotropy needs to be characterised before physical parameter retrieval can take place. Accurate quantification of the anisotropy is undertaken by defining a model which describes the relationship between backscatter and the incidence/azimuth angles. Fraser et al. (2014) showed that a parameterisation featuring a linear falloff of incidence angle with increasing backscatter, plus a $1^{\text {st }}, 2^{\text {nd }}$ and $4^{\text {th }}$ harmonic sinusoidal azimuthal response was a good choice for representing the anisotropy found on most of the Antarctic Ice Sheet. While work on sea ice parameter retrieval is still at a nascent stage, this same parameterisation shows promise in this domain too. Thus, we adopt parameterisation "Linear_124" from Fraser et al. (2014) as a general parameterisation with a wide range of potential applications to the cryosphere. This presents the relationship between these as a surface as a function of the two, $\sigma_{0}=A+f(\theta)+g(\varphi)$ where $\sigma_{0}$ represents the measured backscatter, $\theta$ is the incidence angle and $\varphi$ the azimuth angle of the observation. The "Linear_124" from Fraser et al. (2014) is given in Equation (I) below.

$$
\sigma_{0}=A+B\left(\theta-40^{\circ}\right)+m_{1} \cos \left(1\left(\varphi-\varphi_{1}\right)\right)+m_{2} \cos \left(2\left(\varphi-\varphi_{2}\right)\right)+m_{4} \cos \left(4\left(\varphi-\varphi_{4}\right)\right)
$$

200 Parameterisation is performed separately for the gridded data in the northern and southern hemispheres, and on three different timescales - every 5 days (using data from MetOp-A only), every 2-days (MetOp-A and -B) and daily parameter maps (data from MetOp-A, -B and $-\mathrm{C}$ ). These parameters are detailed below and can be seen in Figures 1-4:

- $A$ - Isotropic component of backscatter (normalised to a mid-range incidence angle of $40^{\circ}$ )

- $\quad B$ - Co-efficient describing the linear falloff of backscatter with increasing incidence angle

- $\quad m_{1}$ and $\varphi_{1}$ - Amplitude and phase of fundamental azimuth anisotropy component

- $\quad m_{2}$ and $\varphi_{2}$ - Amplitude and phase of bisinusoidal azimuth anisotropy component

- $\quad m_{4}$ and $\varphi_{4}$ - Amplitude and phase of 4 th harmonic azimuth anisotropy component

- Residual - Root-mean-square difference between observations and model after parameter-fitting.

210 These data are provided as Climate and Forecasting (CF)-compliant NetCDF4 format, with the date of each time step and all parameter maps along with the latitude and longitude grid in annual files (DOI: 10.26179/5dd60df7469e2)., Data flags are provided in order to identify invalid pixels where there is insufficient data within the time period to accurately parameterise (less than 8 inputs). The coverage of the 1-day product is maximised due to the used of all three satellites, average percentage of invalid pixels remaining separated by latitude can be seen in Figure 6 . 


\section{Dataset Applications}

As presented in Table 1 of Fraser et al. (2014), the majority of previous studies using scatterometry in the cryosphere have applied a linear incidence angle parameterisation. Such studies would be repeatable using the B parameter provided here, in addition to those that feature the $4^{\text {th }}$ order Fourier series azimuth characterisation. It can be seen therefore that these elements are widely used in ice sheet studies, as well as sea ice extent and type as seen in the OSI SAF product (Breivik et al., 2012).

220 The data presented here are suitable for a wide array of cryosphere studies, including sea and glacial ice, as shown by previous applications of the ASCAT sigma0 data. Here these data are taken a step further, accounting for azimuth angle in addition to the incidence angle parameterisations provided by institutions (NOAA and CERSAT products mentioned in Section 1.3). These data are provided on standard grids (NSIDC polar stereographic) in both hemispheres and across a variety of temporal resolutions in order to ensure full geographic coverage, using the sensors on-board all three MetOp satellites and taking

225 advantage of the impressive coverage and consistency of the ASCAT dataset. We provide an extended time series of parameters covering 12 years in the case of the coarsest temporal resolution.

In the future we hope to be able to build and extend this dataset with the launch of the EUMETSAT polar system second generation (EPS-SG) MetOp -SG series, three satellites with proposed SCA scatterometers on-board (Lin et al., 2012), These aim to provide comparable measurements to ASCAT, but with a finer horizontal resolution and a wider swath (Lin et al., 230 2012).

\section{Conclusion}

Here we present a new dataset of scatterometery parameterisations taking advantage of the complete constellation of MetOp satellites in orbit. The use of three platforms (MetOp-A, -B and -C) allows multiple temporal resolutions of the product to be provided and full parameterisations achieved, accounting for both incidence and azimuth angle anisotropy. In this, the product

235 is unique. It is hoped that this parameterisation, proven for cryosphere purposes (Fraser et al., 2014), will encourage the exploitation of scatterometery data for cryosphere science, research and monitoring. This dataset will be updated through the lifetime of the MetOp platforms, and will aim to be continued with the launch of the first of the MetOp-SG series in 2021.

\section{Data Availability}

The source data used for the derivation of these parameters is available from the EUMETSAT Data Centre 240 (http://www.eumetsat.int), under Product "ASCAT GDS Level 1 Sigma0 resampled at 12.5 km Swath Grid - Metop", data code ASCSZR1B. The data presented in this paper are available from Australian Antarctic Data Centre, DOI: 10.26179/5dd60df7469e2 (Fraser and Cartwright, 2021).

Author Contributions: ADF designed the processing, JC applied the processing to the data and packaged the dataset and JC and $\mathrm{ADF}$ wrote, edited and revised the paper. 
https://doi.org/10.5194/essd-2021-92

Preprint. Discussion started: 31 March 2021

(c) Author(s) 2021. CC BY 4.0 License.

(c) (1)

245 Competing interests: The authors declare that they have no conflict of interest.

Acknowledgements: Thanks to the EUMETSAT data centre for making the Level 1B data from ASCAT publicly available for processing, and fulfilling our considerable data requests. This work was supported by the Natural Environmental Research Council (grant NE/L002531/1). This project received grant funding from the Australian Government as part of the Antarctic

250 Climate \& Ecosystems Cooperative Research Centre, the Australian Research Council's Special Research Initiative for Antarctic Gateway Partnership (Project ID SR140300001) and the Antarctic Science Collaboration Initiative program (grant number ASCI000002). This work also contributes to Australian Antarctic Science Project 4301.

\section{Figures}


https://doi.org/10.5194/essd-2021-92

Preprint. Discussion started: 31 March 2021

(c) Author(s) 2021. CC BY 4.0 License.

(c) (i)

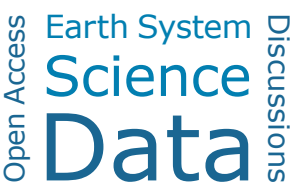
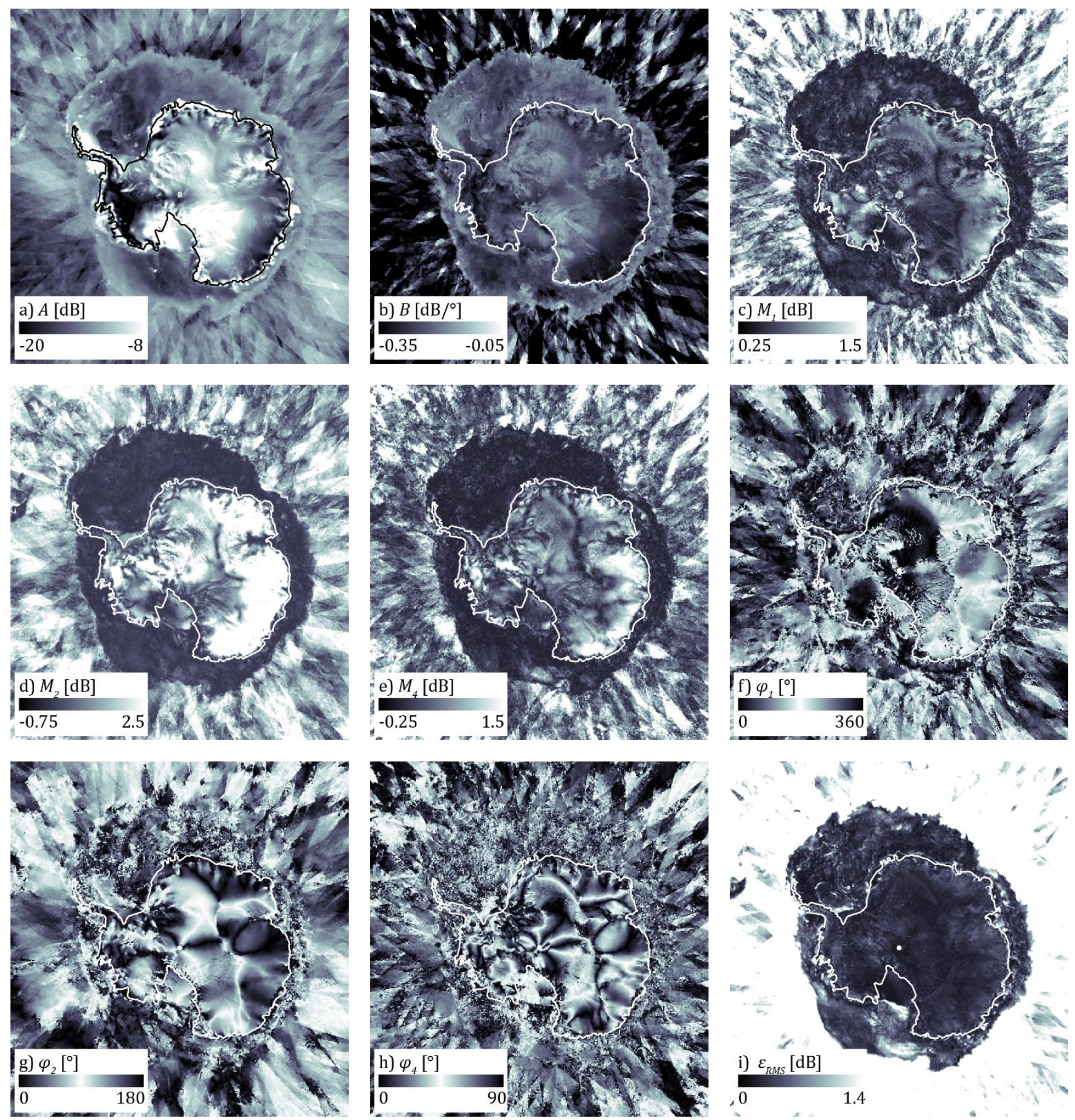

255 Figure 1: Example parameter maps at 5-day resolution over Antarctica and the Southern Ocean, taken from 2017, day of year range 171-175 (20 (th $^{\text {th }}$ 24 $^{\text {th }}$ April, 2017) using data from MetOp-A only. Coastlines outlined in black (a) or white (others, b)-i)) 

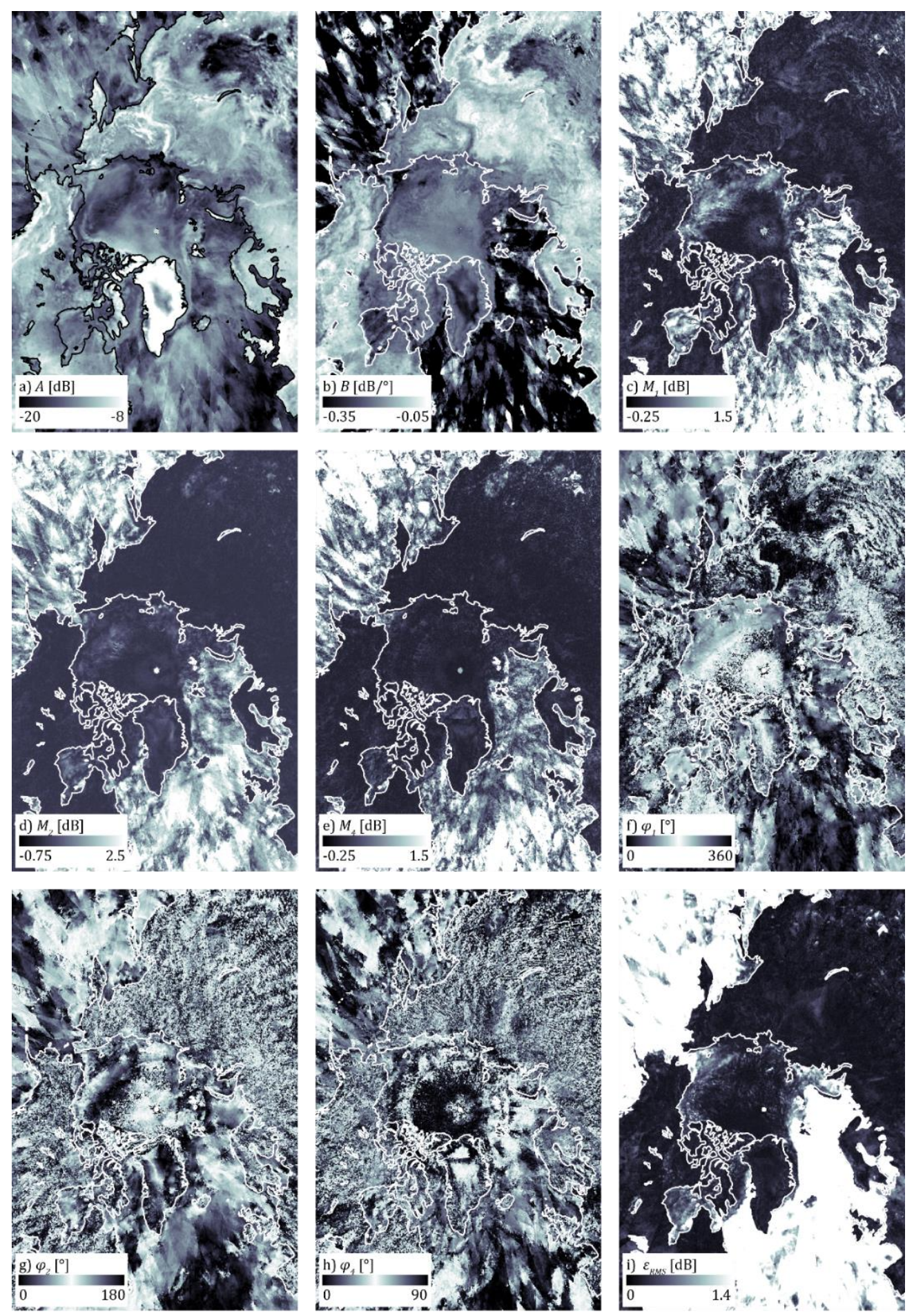

Figure 2: Example parameter maps at 5-day resolution over the Arctic, taken from 2017, day of year range $351-355\left(17^{\text {th }}-21^{\text {st }}\right.$ December, 2017) using data from MetOp-A only. Coastlines outlined in black (a) or white (others, b)-i)). 
https://doi.org/10.5194/essd-2021-92

Preprint. Discussion started: 31 March 2021

(c) Author(s) 2021. CC BY 4.0 License.

(c) (i)

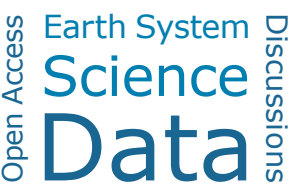
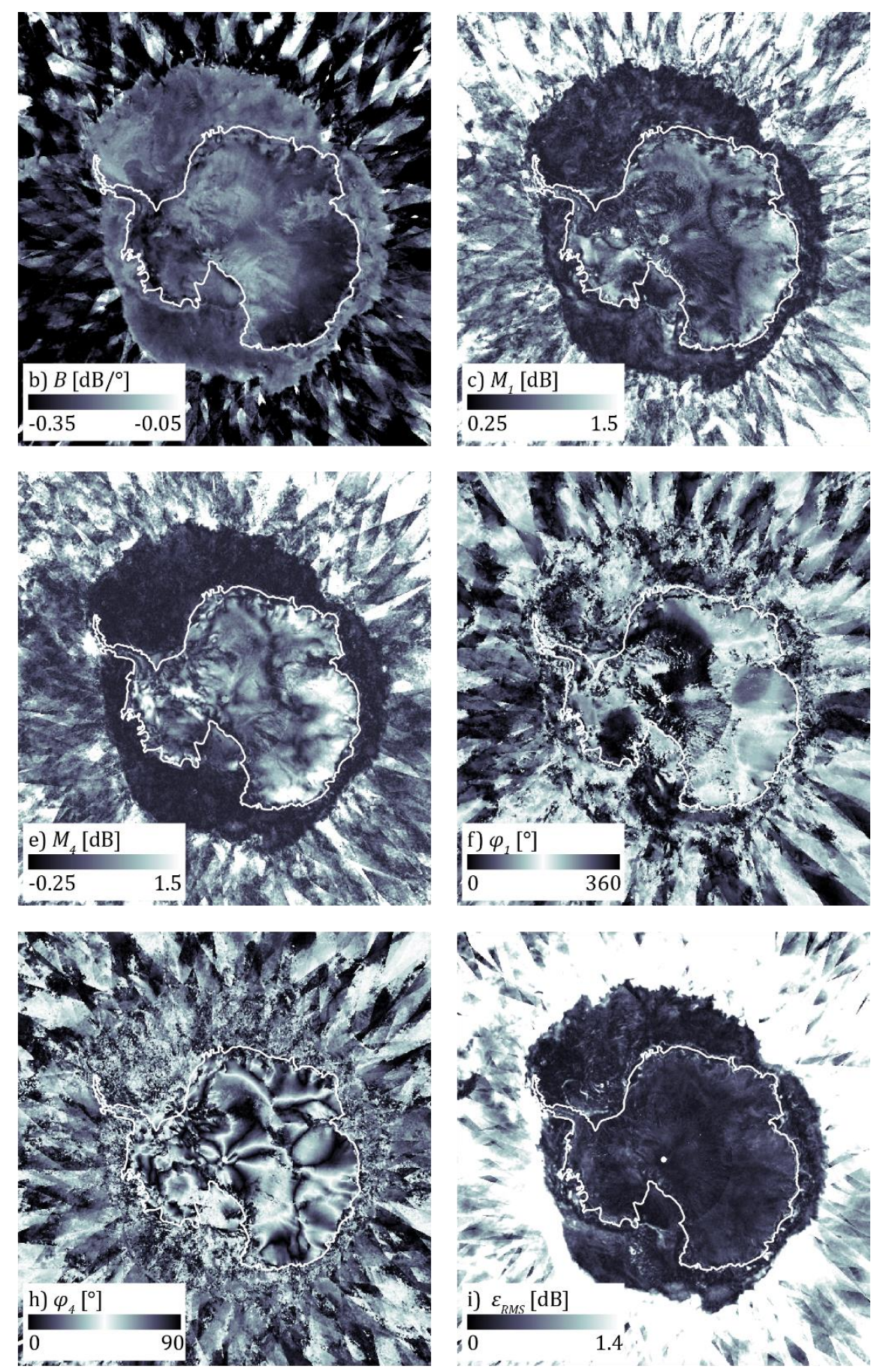

Figure 3: Example parameter maps at 2-day resolution over the Antarctica and the Southern Ocean, taken from 2017, day of year range 171-172 (20th - 21th April, 2017) using data from MetOp-A and -B. Coastlines outlined in black (a) or white (others, b)-i)). 
https://doi.org/10.5194/essd-2021-92

Preprint. Discussion started: 31 March 2021

(c) Author(s) 2021. CC BY 4.0 License.

(c) (i)

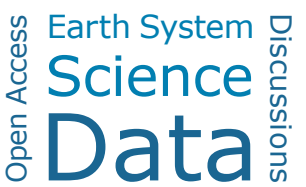
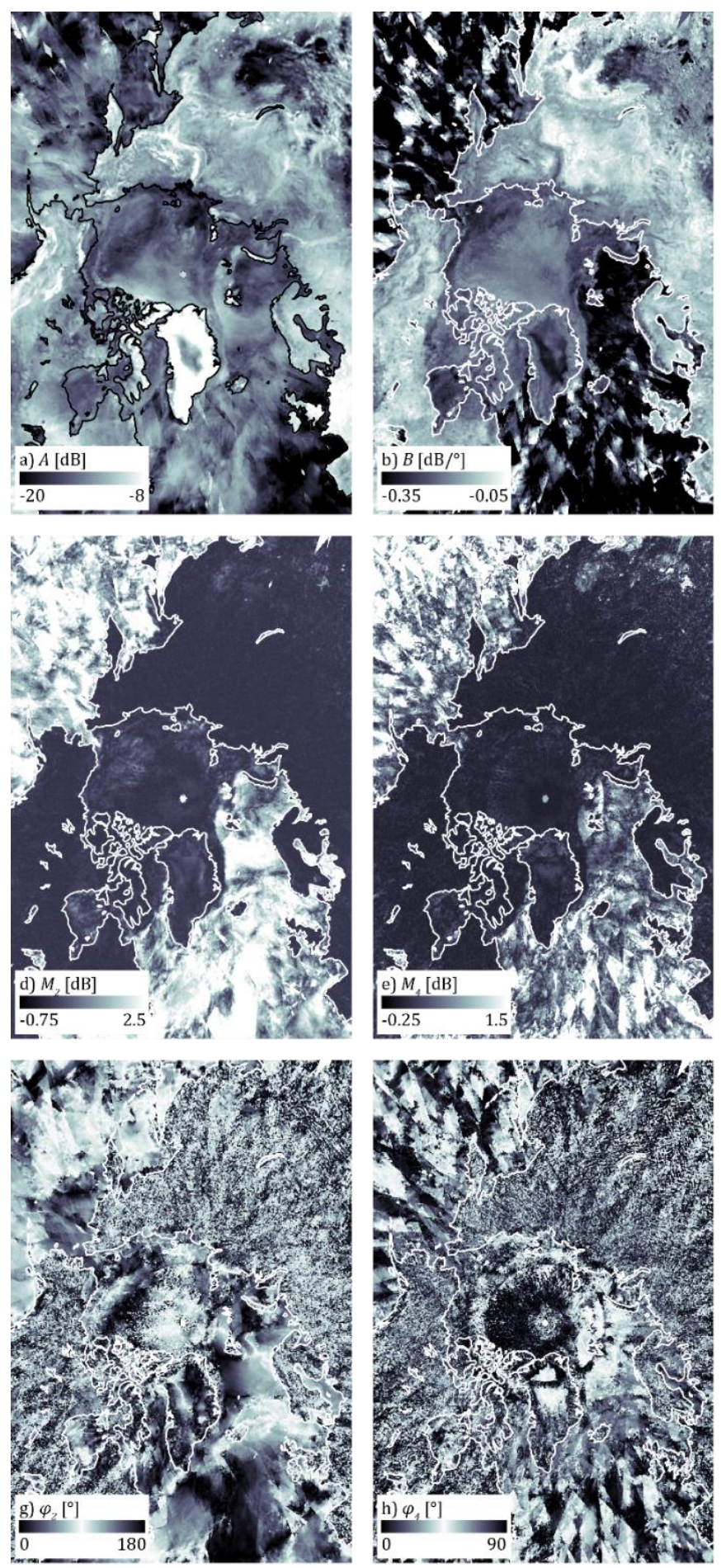

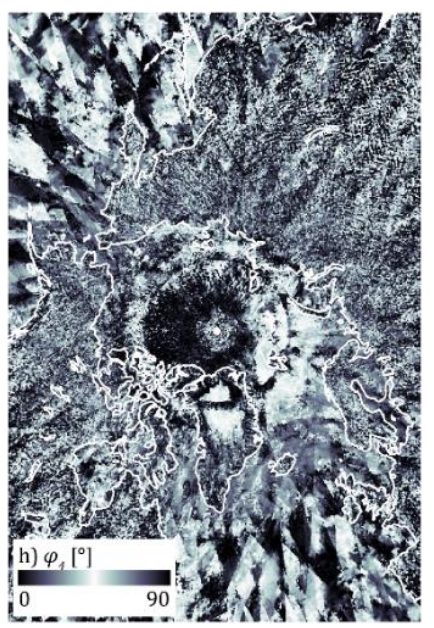

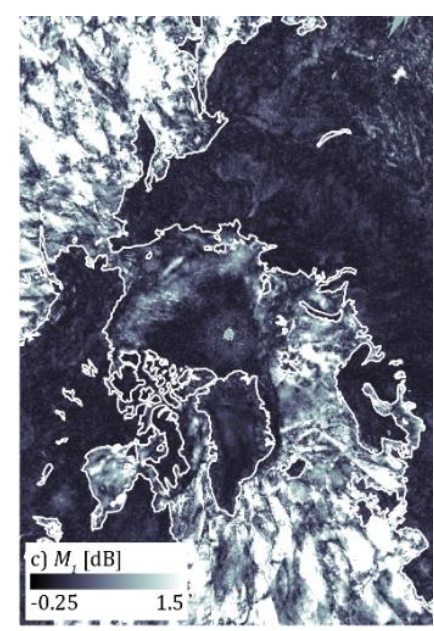
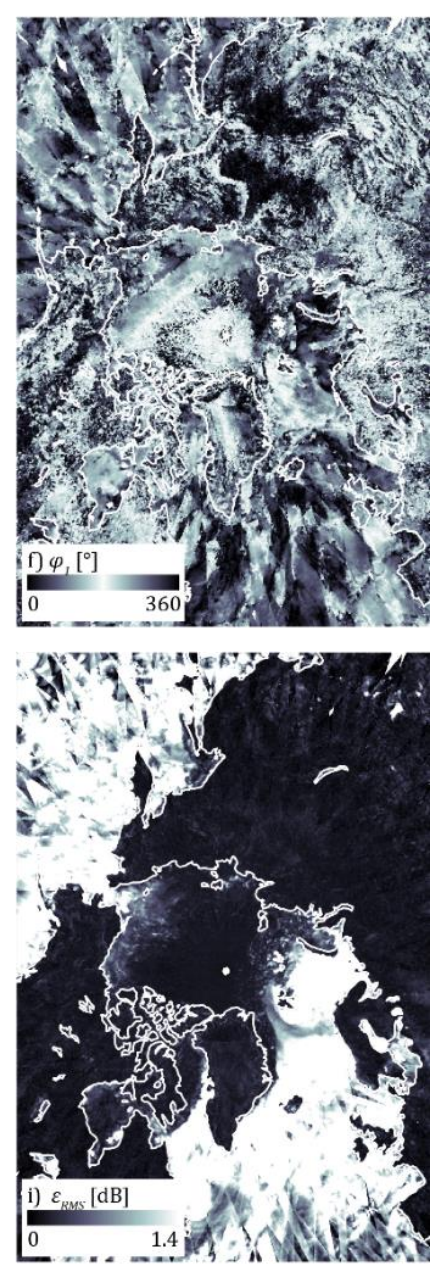

Figure 4: Example parameter maps at 2-day resolution over the Arctic, taken from 2017, day of year range $351-352\left(21^{\text {st }}-22^{\text {nd }}\right.$ December, 2017) using data from MetOp-A and -B. Coastlines outlined in black (a)) or white (b)-i)). 

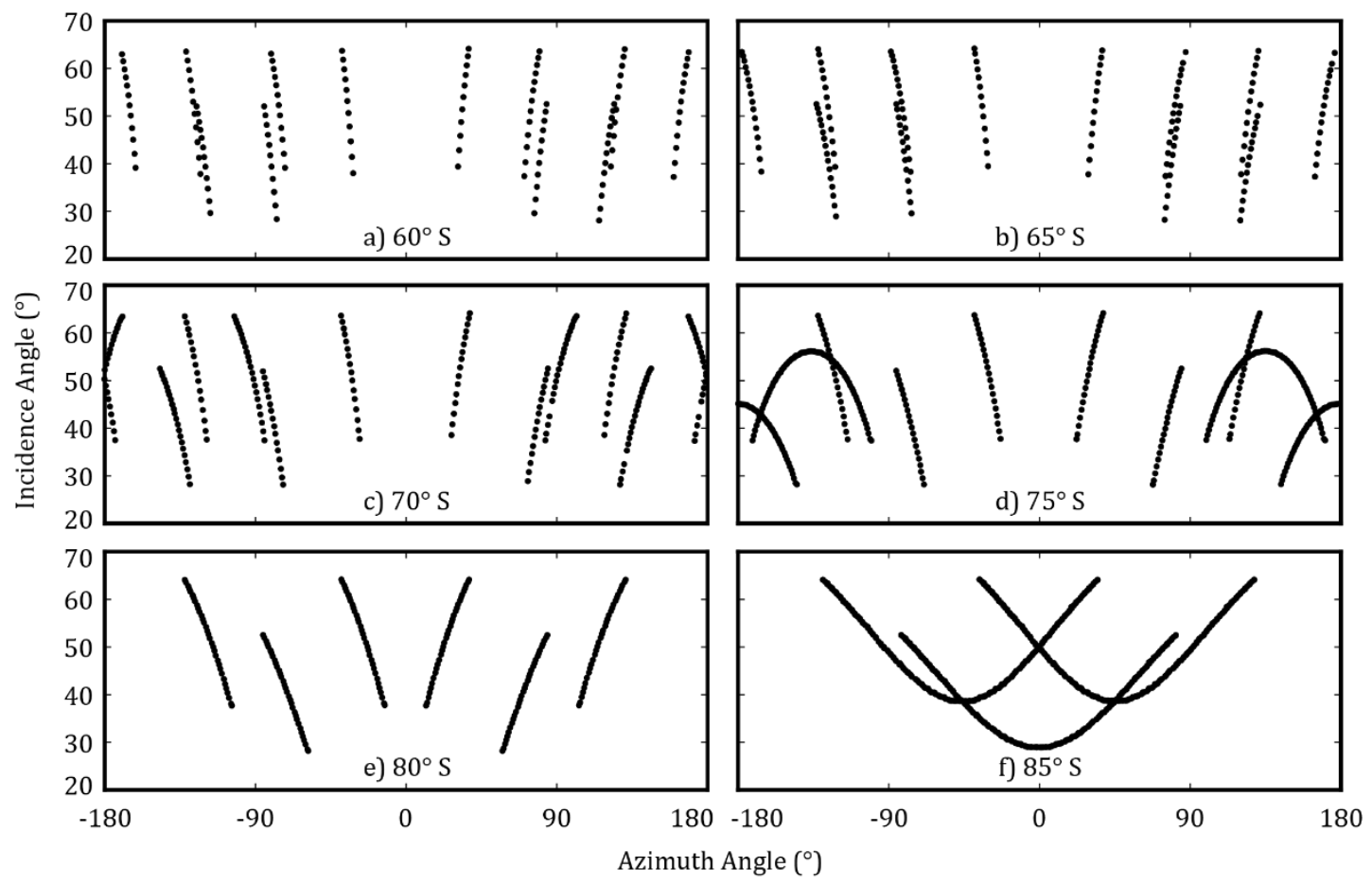

Figure 5: Plot of the azimuth and incidence angle distributions of the scatterometer swaths in the Southern Hemisphere as a function of latitude from a) 45 degrees to j) 90 degrees South from MetOp-B over June 2017.

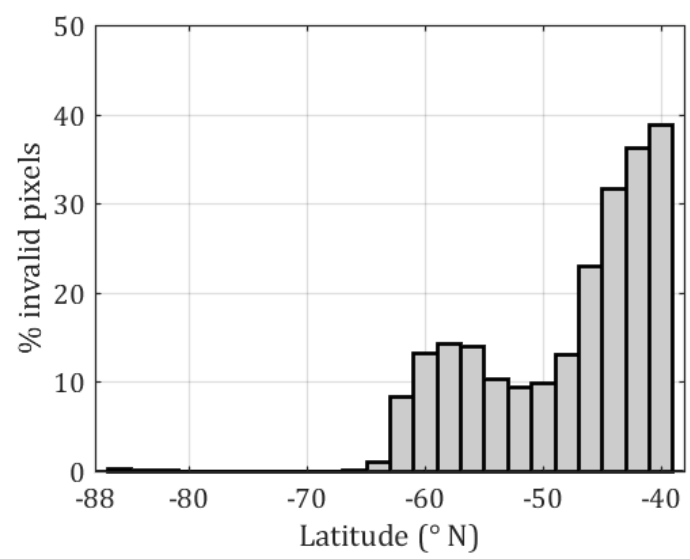

Figure 6: Percentage of invalid pixels by latitude for the data at 1-day resolution over the Southern Hemisphere (Metop-A, -B and $-\mathrm{C})$. 
https://doi.org/10.5194/essd-2021-92

Preprint. Discussion started: 31 March 2021

(c) Author(s) 2021. CC BY 4.0 License.

\section{References}

Alley, K. E.: Studies of Antarctic Ice Shelf Stability: Surface Melting, Basal Melting, and Ice Flow Dynamics, Doctor of Philosophy, Department of Geological Sciences, University of Colorado Boulder, 2017.

Alley, K. E., Scambos, T. A., Miller, J. Z., Long, D. G., and MacFerrin, M.: Quantifying vulnerability of Antarctic ice shelves to hydrofracture using microwave scattering properties, Remote Sensing of Environment, 210, 297-306, 2018.

Ashcraft, I. S. and Long, D. G.: Comparison of methods for melt detection over Greenland using active and passive microwave measurements, International Journal of Remote Sensing, 27, 2469-2488, 2006.

Bartalis, Z., Scipal, K., and Wagner, W.: Azimuthal anisotropy of scatterometer measurements over land, IEEE Transactions on Geoscience and Remote Sensing, 44, 2083-2092, 2006.

285 Bingham, A. W. and Drinkwater, M. R.: Recent changes in the microwave scattering properties of the Antarctic ice sheet, IEEE Transactions on Geoscience and Remote Sensing, 38, 1810-1820, 2000.

Bird, K. J., Charpentier, R. R., Gautier, D. L., Houseknecht, D. W., Klett, T. R., Pitman, J. K., Moore, T. E., Schenk, C. J., Tennyson, M. E., and Wandrey, C. R.: Circum-arctic resource appraisal: Estimates of undiscovered oil and gas north of the Arctic Circle, doi: 10.3133/fs20083049, 2008. 2008.

290 Breivik, L.-A., Eastwood, S., and Lavergne, T.: Use of C-Band Scatterometer for Sea Ice Edge Identification, IEEE Transactions on Geoscience and Remote Sensing, 50, 2669-2677, 2012.

Budge, J. S. and Long, D. G.: A Comprehensive Database for Antarctic Iceberg Tracking Using Scatterometer Data, IEEE Journal of Selected Topics in Applied Earth Observations and Remote Sensing, 11, 434-442, 2018.

Comiso, J. C., Cavalieri, D. J., and Markus, T.: Sea ice concentration, ice temperature, and snow depth using AMSR-E data,

295 IEEE Transactions on Geoscience and Remote Sensing, 41, 243-252, 2003.

Drinkwater, M. R., Long, D. G., and Bingham, A. W.: Greenland snow accumulation estimates from satellite radar scatterometer data, Journal of Geophysical Research: Atmospheres, 106, 33935-33950, 2001.

Figa-Saldaña, J., Wilson, J. J. W., Attema, E., Gelsthorpe, R., Drinkwater, M. R., and Stoffelen, A.: The advanced scatterometer (ASCAT) on the meteorological operational (MetOp) platform: A follow on for European wind scatterometers,

300 Canadian Journal of Remote Sensing, 28, 404-412, 2002.

Fraser, A. D. and Cartwright, J.: Advanced Scatterometer-derived Arctic and Antarctic backscatter anisotropy parameter maps. Australian Antarctic Data Centre, 2021.

Fraser, A. D., Nigro, M. A., Ligtenberg, S. R. M., Legresy, B., Inoue, M., Cassano, J. J., Kuipers Munneke, P., Lenaerts, J. T. M., Young, N. W., Treverrow, A., Van Den Broeke, M., and Enomoto, H.: Drivers of ASCAT C band backscatter variability

305 in the dry snow zone of Antarctica, Journal of Glaciology, 62, 170-184, 2016.

Fraser, A. D., Young, N. W., and Adams, N.: Comparison of Microwave Backscatter Anisotropy Parameterizations of the Antarctic Ice Sheet Using ASCAT, IEEE Transactions on Geoscience and Remote Sensing, 52, 1583-1595, 2014.

Holland, P. R., Bracegirdle, T. J., Dutrieux, P., Jenkins, A., and Steig, E. J.: West Antarctic ice loss influenced by internal climate variability and anthropogenic forcing, Nature Geoscience, 12, 718-724, 2019.

310 Ledroit, M., Remy, F., and Minster, J. F.: Observations of the Antarctic ice sheet with the Seasat scatterometer: relation to katabatic-wind intensity and direction, Journal of Glaciology, 39, 385-396, 1993.

Lin, C.-C., Betto, M., Belmonte Rivas, M., Stoffelen, A., and de Kloe, J.: EPS-SG Windscatterometer Concept Tradeoffs and Wind Retrieval Performance Assessment, IEEE Transactions on Geoscience and Remote Sensing, 50, 2458-2472, 2012.

Long, D. G.: Polar Applications of Spaceborne Scatterometers, IEEE J Sel Top Appl Earth Obs Remote Sens, 10, 2307-2320,

3152017.

Long, D. G. and Drinkwater, M. R.: Azimuth variation in microwave scatterometer and radiometer data over Antarctica, IEEE Transactions on Geoscience and Remote Sensing, 38, 1857-1870, 2000.

Long, D. G., Hardin, P. J., and Whiting, P. T.: Resolution enhancement of spaceborne scatterometer data, IEEE Transactions on Geoscience and Remote Sensing, 31, 700-715, 1993.

320 Lubin, D. and Massom, R.: Polar Remote Sensing: Volume I: Atmosphere and Oceans, Springer Science \& Business Media, 2006.

Massom, R. and Lubin, D.: Polar Remote Sensing: Volume II: Ice Sheets, Springer Berlin Heidelberg, 2005.

Mätzler, C. and Hüppi, R.: Review of signature studies for microwave remote sensing of snowpacks, Advances in Space Research, 9, 253-265, 1989. 
https://doi.org/10.5194/essd-2021-92

Preprint. Discussion started: 31 March 2021

(c) Author(s) 2021. CC BY 4.0 License.

Müller, K., Sinisalo, A., Anschütz, H., Hamran, S.-E., Hagen, J.-O., McConnell, J. R., and Pasteris, D. R.: An 860 km surface mass-balance profile on the East Antarctic plateau derived by GPR, Ann Glaciol, 51, 1-8, 2010.

OSI SAF: Sea ice edge product of the EUMETSAT Ocean and Sea Ice Satellite Application Facility. 2019a.

OSI SAF: Sea ice type product of the EUMETSAT Ocean and Sea Ice Satellite Application Facility. 2019b.

Partington, K. and Flach, D.: Synergetic Use of Remote Sensing Data in Ice Sheet Snow Accumulation and Topographic

Change Estimates: Comparison of model output with available data, Noveltis, Vexcel UK and Legos, 2003.

Pörtner, H., Roberts, D., Masson-Delmotte, V., Zhai, P., Tignor, M., Poloczanska, E., Mintenbeck, K., Nicolai, M., Okem, A., and Petzold, J.: IPCC Special Report on the Ocean and Cryosphere in a Changing Climate, IPCC Intergovernmental Panel on Climate Change: Geneva, Switzerland, 2019. 2019.

Remy, F., Ledroit, M., and Minster, J. F.: Katabatic wind intensity and direction over Antarctica derived from scatterometer

data, Geophysical Research Letters, 19, 1021-1024, 1992.

Rignot, E., Echelmeyer, K., and Krabill, W.: Penetration depth of interferometric synthetic-aperture radar signals in snow and ice, Geophysical Research Letters, 28, 3501-3504, 2001.

Rott, H., Sturm, K., and Miller, H.: Active and passive microwave signatures of Antarctic firn by means of field measurements and satellite data, Ann Glaciol, 17, 337-343, 1993.

340 Shepherd, A., Ivins, E., Rignot, E., Smith, B., van den Broeke, M., Velicogna, I., Whitehouse, P., Briggs, K., Joughin, I., Krinner, G., Nowicki, S., Payne, T., Scambos, T., Schlegel, N., A, G., Agosta, C., Ahlstrøm, A., Babonis, G., Barletta, V. R., Bjørk, A. A., Blazquez, A., Bonin, J., Colgan, W., Csatho, B., Cullather, R., Engdahl, M. E., Felikson, D., Fettweis, X., Forsberg, R., Hogg, A. E., Gallee, H., Gardner, A., Gilbert, L., Gourmelen, N., Groh, A., Gunter, B., Hanna, E., Harig, C., Helm, V., Horvath, A., Horwath, M., Khan, S., Kjeldsen, K. K., Konrad, H., Langen, P. L., Lecavalier, B., Loomis, B., Luthcke,

345 S., McMillan, M., Melini, D., Mernild, S., Mohajerani, Y., Moore, P., Mottram, R., Mouginot, J., Moyano, G., Muir, A., Nagler, T., Nield, G., Nilsson, J., Noël, B., Otosaka, I., Pattle, M. E., Peltier, W. R., Pie, N., Rietbroek, R., Rott, H., Sandberg Sørensen, L., Sasgen, I., Save, H., Scheuchl, B., Schrama, E., Schröder, L., Seo, K.-W., Simonsen, S. B., Slater, T., Spada, G., Sutterley, T., Talpe, M., Tarasov, L., van de Berg, W. J., van der Wal, W., van Wessem, M., Vishwakarma, B. D., Wiese, D., Wilton, D., Wagner, T., Wouters, B., Wuite, J., and The, I. T.: Mass balance of the Greenland Ice Sheet from 1992

350 to 2018, Nature, 579, 233-239, 2020.

Spencer, M. W., Chialin, W., and Long, D. G.: Tradeoffs in the design of a spaceborne scanning pencil beam scatterometer: application to SeaWinds, IEEE Transactions on Geoscience and Remote Sensing, 35, 115-126, 1997.

Stroeve, J. C., Serreze, M. C., Holland, M. M., Kay, J. E., Malanik, J., and Barrett, A. P.: The Arctic's rapidly shrinking sea ice cover: a research synthesis, Climatic Change, 110, 1005-1027, 2011.

355 Trusel, L. D., Frey, K. E., and Das, S. B.: Antarctic surface melting dynamics: Enhanced perspectives from radar scatterometer data, Journal of Geophysical Research: Earth Surface, 117, 2012.

Ulaby, F. T., Siquera, P., Nashashibi, A., and Sarabandi, K.: Semi-empirical model for radar backscatter from snow at 35 and 95 GHz, IEEE Transactions on Geoscience and Remote Sensing, 34, 1059-1065, 1996.

Vogelzang, J. and Stoffelen, A.: ASCAT Ultrahigh-Resolution Wind Products on Optimized Grids, IEEE Journal of Selected

360 Topics in Applied Earth Observations and Remote Sensing, 10, 2332-2339, 2017.

Young, N. W. and Hyland, G.: Applications of time series of microwave backscatter over the Antarctic region, Florence, Italy, 1997 1997, 1007, 1997.

Yurchak, B.: Some Features of the Volume Component of Radar Backscatter from Thick and Dry Snow Cover. In: Advances in Geoscience and Remote Sensing, Jedlovec, G. (Ed.), Intech, Rijeka, Croatia, 2009. 